\title{
QUEEN'S
UNIVERSITY
BELFAST
}

\section{Serum- and HDL3-serum amyloid A and HDL3-LCAT activity are influenced by increased CVD-burden}

McEneny, J., McKavanagh, P., York, E., Nadeem, N., Harbinson, M., Stevenson, M., Ball, P., Lusk, L., Trinick, T., Young, I. S., McKay, G. J., \& Donnelly, P. M. (2016). Serum- and HDL3-serum amyloid A and HDL3-LCAT activity are influenced by increased CVD-burden. Atherosclerosis, 244, 172-178.

https://doi.org/10.1016/j.atherosclerosis.2015.11.018

Published in:

Atherosclerosis

Document Version:

Peer reviewed version

Queen's University Belfast - Research Portal:

Link to publication record in Queen's University Belfast Research Portal

Publisher rights

Copyright (C) 2015 Elsevier B.V.This manuscript version is made available under the CC-BY-NC-ND 4.0 license

http://creativecommons.org/licenses/by-nc-nd/4.0/ which permits distribution and reproduction for non-commercial purposes, provided the author and source are cited

\section{General rights}

Copyright for the publications made accessible via the Queen's University Belfast Research Portal is retained by the author(s) and / or other copyright owners and it is a condition of accessing these publications that users recognise and abide by the legal requirements associated with these rights.

Take down policy

The Research Portal is Queen's institutional repository that provides access to Queen's research output. Every effort has been made to ensure that content in the Research Portal does not infringe any person's rights, or applicable UK laws. If you discover content in the Research Portal that you believe breaches copyright or violates any law, please contact openaccess@qub.ac.uk. 
SAA and its relationship to CVD-burden

Serum- and HDL3-Serum Amyloid A and HDL3-LCAT activity are influenced by increased CVD-burden

Running title: SAA and LCAT and CVD-burden

Jane McEneny ${ }^{1 *}$, Peter McKavanagh ${ }^{2},{\text { Edmund } \text { York }^{1} \text {, Nida Nadeem }}^{1}$, Mark Harbinson ${ }^{1}$, Michael Stevenson ${ }^{1}$,

Peter Ball², Lisa Lusk ${ }^{2}$, Thomas Trinick ${ }^{3}$, Ian S Young ${ }^{1}$, Gareth J McKay ${ }^{1}$, Patrick M Donnelly ${ }^{2}$

${ }^{I}$ Centre for Public Health, Queen's University Belfast, Belfast, United Kingdom.

${ }^{2}$ Cardiovascular Research Department, Ulster Hospital, Belfast, United Kingdom.

${ }^{3}$ Clinical Biochemistry, Ulster Hospital, Belfast, United Kingdom.

*Corresponding Author: Centre for Public Health, Queen's University Belfast, Ground Floor, Pathology

Building, RVH Site, Grosvenor Road, Belfast, BT12 6BJ, UK.

Tel; ++44 28 90632517. FAX: ++44 28 90235900. Email: J.McEneny@qub.ac.uk

Tables: 4

Ethics number-10/NIR01/51 
SAA and its relationship to CVD-burden

\begin{abstract}
Background: High density lipoproteins (HDL) protect against cardiovascular disease (CVD). However, increased serum amyloid-A (SAA) related inflammation may negate this property. This study investigated if SAA was related to CVD-burden.
\end{abstract}

Methods: Subjects referred to the rapid chest pain clinic $(n=240)$ had atherosclerotic burden assessed by cardiac computerised tomography angiography. Subjects were classified as: no-CVD ( $\mathrm{n}=106)$, non-obstructive-CVD, stenosis $<50 \%(\mathrm{n}=58)$ or moderate/significant-CVD, stenosis $\geq 50 \%$ ( $\mathrm{n}=76)$. HDL was subfractionated into $\mathrm{HDL}_{2}$ and $\mathrm{HDL}_{3}$ by rapid-ultracentrifugation. SAA-concentration was measured by ELISA and lecithin cholesterol acyltransferase (LCAT) activity measured by a fluorimetric assay.

Results: We illustrated that serum-SAA and $\mathrm{HDL}_{3}$-SAA-concentration were higher and $\mathrm{HDL}_{3}$-LCAT-activity lower in the moderate/significant-CVD-group, compared to the no-CVD and non-obstructive-CVD-groups (percent differences: serum-SAA, $+33 \% \&+30 \%$ : $\mathrm{HDL}_{3}-\mathrm{SAA},+65 \%$ and $+39 \%$ : $\mathrm{HDL}_{3}-\mathrm{LCAT},-6 \% \&-3 \%$; $\mathrm{p}<0.05$ for all comparisons). We also identified a positive correlation between serum-SAA and $\mathrm{HDL}_{3}-\mathrm{SAA}$

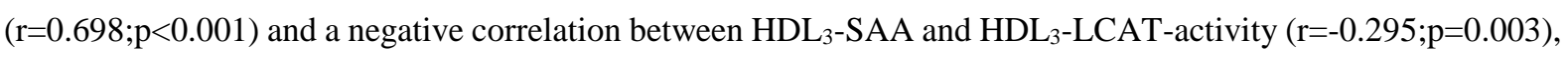
while CVD-burden positively correlated with serum-SAA $(r=0.150 ; p<0.05)$ and $\mathrm{HDL}_{3}$-SAA $(r=0.252 ; \mathrm{p}<0.001)$ and negatively correlated with $\mathrm{HDL}_{3}$-LCAT-activity $(\mathrm{r}=-0.182 ; \mathrm{p}=0.006)$. Additionally, multivariate regression analysis adjusted for age, gender, CRP and serum-SAA illustrated that $\mathrm{HDL}_{3}-\mathrm{SAA}$ was significantly associated with modifying CVD-risk of moderate/significant CVD-risk $(\mathrm{p}<0.05)$.

Conclusion: This study has demonstrated increased SAA-related inflammation in subjects with moderate/significant CVD-burden, which appeared to impact on the antiatherogenic potential of HDL. We suggest that SAA may be a useful biomarker to illustrate increased CVD-burden, although this requires further investigation.

227 words

Keywords: Serum amyloid A, HDL, LCAT activity, CVD-burden 
SAA and its relationship to CVD-burden

\section{Introduction}

It has become increasingly apparent that chronic inflammation plays a major role in the development of cardiovascular disease (CVD)[1,2] and it is clear that established risk factors do not fully explain its development. As a consequence there is increasing interest in the use of novel biochemical markers for the assessment of atherosclerosis and the prediction of cardiovascular risk. Many cytokines and chemokines have been implicated in promoting various stages of the atherosclerotic process, including interleukin (IL)-1, IL-2, IL-6, tumour necrosis factor $\alpha(\mathrm{TNF}-\alpha)$, interferon- $\gamma$ and monocyte chemo-attractant protein-1 (MCP-1). Some of these primary signalling molecules are released from activated immune cells, such as macrophages; in response to endothelial damage early in the atherosclerotic process. The release of chemokines attracts macrophages and platelets, while the pro-inflammatory cytokines induce proliferation and differentiation of immune cells and smooth muscle cells. Eventually, sufficiently elevated cytokine levels may lead to systemic effects, with several plasma inflammatory biomarkers being measureable, including C-reactive protein (CRP)[3] and serum amyloid A (SAA)[4].

Although the protective role of high density lipoproteins (HDL) against the development of CVD is well established[5,6], this role may be diminished when SAA associates with this lipoprotein. This association alters the physicochemical properties of HDL[7], particularly the smaller HDL subfraction, $\mathrm{HDL}_{3}[8]$, causing it to become dysfunctional. Dysfunctional HDL binds to proteoglycans on the vascular wall, favouring their retention and modification by the vascular matrix. It also enhances cholesterol ester uptake into macrophages and reduces reverse cholesterol transport (RCT) $[9,10]$, as demonstrated by the ex vivo and in vitro experiments of Heinecke's group[11]. Dysfunctional HDL induces the release of pro-inflammatory cytokines[12], enhances the recruitment of monocytes into vascular plaques[13] and causes macrophage accumulation[14], thus helping propagate the inflammatory process. Furthermore, SAA impairs the antioxidant function of HDL[15], while the activity of HDL remodelling enzymes, such as lecithin cholesterol acyltransferase (LCAT), an enzyme that is responsible for the esterification of free cholesterol within $\mathrm{HDL}_{3}$ and thus its maturation to $\mathrm{HDL}_{2}$, is reduced by the presence of SAA[16]. However, the role of LCAT in the atherosclerotic process remains discordant[17], as reviewed[18].

The presence of CVD may be assessed by cardiac computerised tomography angiogram (CCTA), which is an effective and non-invasive way to assess atherosclerotic burden in low to intermediate-risk patients[19]. However, the cost implications of CCTA may prohibit its widespread use. Therefore, the primary aim of this study was to assess if measuring SAA could indicate CVD-burden/presence and indicate more proatherogenic HDL, meaning that it could be used alongside CCTA or as a surrogate of CVD presence, if CCTA was unavailable. The 
SAA and its relationship to CVD-burden

secondary aim was to assess if the LCAT in $\mathrm{HDL}_{2}$ and $\mathrm{HDL}_{3}$ was altered to a more proatherogenic phenotype in the presence of SAA, potentially increasing CVD-risk. These aims were examined in an adult population that had been referred for investigation with suspected ischaemic cardiac chest pain and who had CVD-burden classified by $\mathrm{CT}$ imaging and calcium scoring. 
SAA and its relationship to CVD-burden

\section{Methods and Materials}

Ethics was obtained from the Office for Research Ethics Committees for Northern Ireland (ID number: 10/NIR01/51).

\subsection{Patient population}

The subjects for this cross-sectional study were enrolled in the Cardiac-CT for the Assessment of Pain and Plaque (CAPP)-Study (ISRCTN52480460), as previously described in detail[20]. In brief, these subjects had been referred for investigation with suspected ischaemic cardiac chest pain, without symptoms suggestive of unstable angina. Subjects $(n=500)$, were assigned into one of two arms. In the first arm, CVD presence was assessed by conventional stress test $(n=250)$, in the second arm, CVD burden was assessed by calcium scoring and CT imaging by $\operatorname{CCTA}(n=250)$.

The current study utilised serum from the subjects randomised to the CT arm $(n=250)$. Any subject defined as having an active infection (hsCRP $>10,000 \mu \mathrm{g} / \mathrm{L}$ ) were excluded from the analyses, in accordance with American Heart Association Guidelines[21]. A further 4 subjects withdrew, leaving a total population of 240 subjects in this CT arm. These subjects were classified according to CVD-burden using the American Heart Association's 15 point scale[22], which is a division of the coronary tree divided into 15 parts, multiplied by the severity of stenosis in each part. Subjects were assigned into one of the three groups according to the absence/presence of CVD: 1) no-CVD ( $\mathrm{n}=106)$; 2) non-obstructive-CVD, area of stenosis $<50 \%(\mathrm{n}=58) ; 3)$ moderate/significant-CVD, area of stenosis $>50 \%$, minimum luminal area $>4 \mathrm{~mm}^{2}(\mathrm{n}=76)$. Calcium scores $(\mathrm{CS})$ were performed by a non-enhanced low radiation scan that produces a series of stacked transaxial images, which can allow an assessment of the volume of calcium present in a patient's coronary arteries.

\section{Exclusion criteria}

Exclusion criteria were a history of contrast media reaction, previous known coronary disease, BMI >35 $\mathrm{kg} / \mathrm{m}^{2}$, tachyarrhythmia, impaired renal function with an estimate GFR $<35 \mathrm{ml} / \mathrm{min}$, uncontrolled hypertension $>220 / 100 \mathrm{mmHg}$, severe peripheral vascular disease, left bundle branch block or any other clinical reason that attending the clinic might compromise the patient's safety.

\subsection{Blood Processing}

Fasting blood was collected into standard serum tubes by the vacuette system. Serum was obtained by centrifugation at $3000 \mathrm{rpm}$ for 15 minutes at $4^{\circ} \mathrm{C}$ and frozen at $-80^{\circ} \mathrm{C}$ in $1.3 \mathrm{~mL}$ aliquots, until required for further analysis. 
SAA and its relationship to CVD-burden

\subsection{Primary Subject Analyses}

Baseline measurements included fasting serum total cholesterol, triglycerides, HDL cholesterol and LDL cholesterol and were measured using standard enzymatic assays on an automated ILab-600 biochemical analyser (Cobas Roche Diagnostics, West Sussex, UK). High sensitive C-reactive protein (hsCRP) was measured by an ELISA procedure using a commercial available kit (BioCheck Inc., Foster City, USA). Height (cm) and weight (kg) were collected using a stadiometer and calibrated scales, and used to determine BMI $\left(\mathrm{kg} / \mathrm{m}^{2}\right)$.

\subsection{Isolation of $\mathrm{HDL}_{2}$ and $\mathrm{HDL}_{3}$ from Serum}

$\mathrm{HDL}_{2}$ and $\mathrm{HDL}_{3}$ were isolated by rapid ultracentrifugation from freshly thawed serum according to the method of McPherson et al[23]. This involved a 3-step, 6-hour long procedure, whereby crude (c)HDL was isolated by rapid sedimentation ultracentrifugation (2-hours), followed by its subfractionation into $\mathrm{HDL}_{2}$ and $\mathrm{HDL}_{3}$ by $2 \times 2$-hour sequential rapid flotation ultracentrifugation procedures. HDL samples were then stored at $80^{\circ} \mathrm{C}$ and batch analysed.

Results are presented as both non-protein standardised and protein standardised. The non-protein standardised results illustrate the levels of biomarker (SAA and LCAT) in the sample as a whole, while the protein standardised result provide a surrogate marker of the level of biomarker (SAA and LCAT) in an individual HDL particle.

\subsection{Serum, $\mathrm{HDL}_{2}$ and $\mathrm{HDL}_{3}-\mathrm{SAA}$}

The concentration of SAA was measured in serum, $\mathrm{HDL}_{2}$ and $\mathrm{HDL}_{3}$ by a commercially available ELISA procedure, which measures SAA-1 (Invitrogen, Human SAA KHA0011C). SAA was assessed on a Grifols TRITURUS automated ELISA system (Italy), as per the manufacturer's instructions, with the following modifications: Serum was diluted 1:150, $\mathrm{HDL}_{2}$ was diluted 1:10 and $\mathrm{HDL}_{3}$ diluted 1:100 prior to analysis. The intra-assay CVs for serum-, $\mathrm{HDL}_{2}$ - and $\mathrm{HDL}_{3}$-SAA were 2.8, 3.7 and 5.6\%, respectively, while their inter-assay CVs were $8,9.5$ and $11 \%$, respectively. Non-protein standardised results are presented as $\mu \mathrm{g} / \mathrm{L}$, which is the absolute concentration in the serum or in the $\mathrm{HDL}_{2}$ and $\mathrm{HDL}_{3}$ subfractions after isolation. In addition, $\mathrm{SAA}$ associated with $\mathrm{HDL}_{2}$ and $\mathrm{HDL}_{3}$ was also standardised for protein concentration and is presented as $\mu \mathrm{g} \mathrm{SAA} / \mathrm{mg}$ protein. 


\subsection{HDL 2 and HDL3-LCAT Activity and Mass}

The activity of LCAT was measured by a fluorimetric procedure (RB-LCAT; Roar Biomedical, NY, US), as per the manufacturer's instructions, using $5 \mu \mathrm{L}$ of either serum, $\mathrm{HDL}_{2}$ or $\mathrm{HDL}_{3}$. This assay was based on the ratio of the substrate reagent (phosphatidylcholine), which has two distinct peaks, 390nm and 470nm. The relative intensity of the peaks depends upon the concentration of the hydrolysed (390nm peak) and the non-hydrolysed (470nm peak) phosphatidylcholine. After hydrolysis of phosphatidylcholine by the source of LCAT (i.e. serum, $\mathrm{HDL}_{2}$ or $\mathrm{HDL}_{3}$ from the subject population) there was a shift in the emission spectrum, with an increase in the $390 \mathrm{~nm}$ emission at the expense of the 470nm emission peak. Results are expressed as a ratio of these emitters, the greater the ratio, the higher the LCAT activity.

LCAT mass was measured by an ELISA procedure (E98516Hu-USC, Stratech, Suffolk, UK), following the manufacturer's instructions, with the following dilutions: serum 1:4000; $\mathrm{HDL}_{2}$ 1:2500; $\mathrm{HDL}_{3}$ 1:3000.

The intra-assay $\mathrm{CVs}_{\mathrm{s}}$ for $\mathrm{HDL}_{2}$ - and $\mathrm{HDL}_{3}$-LCAT activity were both $<1.0 \%$, while their inter-assay $\mathrm{CVs}$ were 4.4 and $1.0 \%$, respectively. The intra-assay $\mathrm{CVs}_{\text {s }}$ for $\mathrm{HDL}_{2^{-}}$and $\mathrm{HDL}_{3}-\mathrm{LCAT}$ mass were 11 and $4 \%$, respectively, while their inter-assay CVs were 17 and $11 \%$, respectively. LCAT mass was expressed as $\mu \mathrm{g} / \mathrm{L}$.

\subsection{Statistical Analysis}

Statistical analysis was performed using SPSS Statistics version 21.0. Variables were assessed for normality and logarithmically transformed where required. Results are reported as mean (standard deviation; SD) when normally distributed, as geometric mean (interquartile range; IQ) when normally distributed after logarithmic transformation. Trends across the groups were analysed by One-Way ANOVA with LSD (least significant difference) post hoc analyses to assess differences between groups. Correlations were assessed using Pearson's correlation coefficient. The assessment of associations of covariates with CVD risk (which is defined as the presence of any CVD, compared to no CVD or significant CVD compared to no or mild CVD) was obtained using a logistic regression model. Age was included in the model as a continuous variable. A value for the area under the ROC (receiver operator characteristics) curve (AUC), also known as the C statistic, was evaluated by using phenotypes with any symptoms of CVD vs. those with no-CVD. A method to compare the area under two ROC curves derived from paired measurements was used to assess the value of adding extra variables to the prediction equation[24], as a measure of overall diagnostic performance (95\% confidence intervals; CI). Four models were used: model 1-gender; model 2-age; model 3-gender+age; model 4-gender+age+HDL ${ }_{3}-\mathrm{SAA}_{\text {. }}$ Significance was set as $\mathrm{p} \leq 0.05$ for all analyses. 


\section{Experimental Results}

\subsection{Subject characteristics according to CVD-burden}

Subject characteristics have previously been described[20]. However, for completeness they are included in table 1, where BMI, triglycerides and LDL-cholesterol were comparable between the groups ( $p>0.05$ for all trends across the groups). Age significantly increased in line with CVD-burden ( $\mathrm{p}<0.001$ for trend across the groups). There was also a gender difference between the groups ( $<<0.05$ for trend across the groups). Specifically, there were fewer males in the group with no-CVD, compared to the two groups with documented CVD $(\mathrm{p}<0.001$ for both comparisons). Total cholesterol was also different across the groups, ( $\mathrm{p}<0.05$ for trend across the groups), which was driven by the significantly higher total cholesterol in the no-CVD group, compared to the group with moderate/significant-CVD ( $\mathrm{p}=0.003)$. HDL-cholesterol was significantly different across the groups ( $\mathrm{p} \leq 0.001$ for trend across the groups), which was driven by the higher HDL-cholesterol in the group with no-CVD, compared to the two groups with documented CVD ( $\mathrm{p}=0.005$ and $\mathrm{p}=0.001$, respectively). As expected and according to group assignment, area of stenosis increased across the groups ( $\mathrm{p}<0.001$ for trend across the groups), which was driven by the greater area of stenosis in the group with moderate/significant-CVD, compared to the other two groups ( $\mathrm{p}<0.001$ for both comparisons) and between the non-obstructive-CVD group and the no-CVD group $(\mathrm{p}<0.001)$. There was a similar trend for calcium scores $(\mathrm{p}<0.001$ for trend across the groups). A similar number of subjects had type 2 diabetes, were smokers and were on hypertensive medications. However, statin therapy differed across the groups ( $\mathrm{p}<0.001$ for trends across the groups). In this case, statin therapy was significantly lower in the group with no-CVD, compared to the non-obstructive and moderate/significant-CVD groups ( $\mathrm{p}=0.006$ and $<0.001$, respectively). There was no difference in statin therapy between the two groups with documented CVD $(\mathrm{p}=0.271)$.

\subsection{Serum-hsCRP and serum-SAA concentration according to CVD-burden}

A positive relationship was identified between serum-hsCRP and serum-SAA $(r=0.267, p<0.001)$. Although serum-hsCRP concentration was not influenced by CVD-burden (table 2; $>>0.05$ for trend across the groups), post hoc analyses revealed increased serum-hsCRP in the group with moderate/significant-CVD, compared to the group with no-CVD ( $\mathrm{p}=0.049)$, but not between the two groups with documented CVD $(\mathrm{p}=0.620)$. However, serum-SAA was influenced by CVD-burden (table 2; $<<0.05$ for trend across the groups), where it was $33 \%$ and $30 \%$ higher the group with moderate/severe-CVD, compared to the no-CVD and non-obstructive groups ( $\mathrm{p}=0.02$ and 0.05 , respectively). Serum-SAA was not different between the no-CVD and non-obstructive-CVD groups $(\mathrm{p}=0.855)$. 


\section{HDL2 and HDL3-SAA concentration according to CVD-burden}

HDL2: Non-protein standardised $\mathrm{HDL}_{2}$-SAA was not related to CVD-burden (table 2; $>0.05$ for trend across the groups). However, when $\mathrm{HDL}_{2}$-SAA was standardised to protein, we fund that its levels were related to CVDburden (table $2 ; \mathrm{p}<0.05$ for trends across the groups). Post-hoc analyses illustrated that this was related to the $58 \%$ increase in its levels in the group with moderate/severe-CVD, compared to the group with no-CVD (p=0.004). However, in spite of the protein standardised $\mathrm{HDL}_{2}$-SAA being $40 \%$ higher in the non-obstructive-CVD group, compared to the group with no-CVD, this only approached significance $(\mathrm{p}=0.064)$. There was no difference in protein standardised $\mathrm{HDL}_{2}$-SAA between the non-obstructive and moderate/significant-CVD groups $(\mathrm{p}=0.436)$. HDL3: $\mathrm{HDL}_{3}$-SAA was related to CVD-burden, whether non-protein standardised or protein standardised (table $2 ; \mathrm{p}<0.05$ and $\mathrm{p}<0.001$, respectively for trend across the groups). For the non-protein standardised $\mathrm{HDL}_{3}-\mathrm{SAA}_{\text {, }}$ its concentration was $41 \%$ and $43 \%$ higher in the group with moderate/significant-CVD, compared to the no-CVD and non-obstructive-CVD groups ( $\mathrm{p}=0.012$ and 0.024 , respectively). For the protein standardised $\mathrm{HDL}_{3}-\mathrm{SAA}_{\text {, its }}$ concentration was $65 \%$ and $39 \%$ higher in the group with moderate/significant-CVD, compared to the no-CVD and non-obstructive-CVD groups ( $\mathrm{p}=0.001$ and 0.014 , respectively). There was no difference between the noCVD and non-obstructive-CVD groups for both non-protein and protein standardised $\mathrm{HDL}_{3}-\mathrm{SAA}$ ( $\mathrm{p}=0.961$ and 0.295 , respectively).

\subsection{HDL 2 and HDL 3 -LCAT activity and mass according to CVD-burden}

HDL2: the activity and mass of LCAT was not different across or between the groups (table 3: $p>0.05$ for both trends across the groups).

HDL3: LCAT activity was related to CVD-burden ( $\mathrm{p}<0.05$ for trend across the groups), where its activity was $6 \%$ and $3 \%$ lower in the group with moderate/significant-CVD, compared to the no-CVD and non-obstructive groups $(\mathrm{p}=0.007$ and 0.036 , respectively). There was no difference in LCAT activity between the no-CVD and nonobstructive-CVD groups ( $\mathrm{p}>0.05$ ). $\mathrm{HDL}_{3}$ LCAT mass was not different between the groups (table 3; $\mathrm{p}>0.05$ for trend across the groups).

\section{Correlations between CVD-burden and SAA concentration and LCAT activity}

Serum: the concentration of SAA was positively correlated with $\mathrm{HDL}_{2}$ and $\mathrm{HDL}_{3}-\mathrm{SAA}(\mathrm{r}=0.585, \mathrm{p}<0.001$ : $\mathrm{r}=0.698, \mathrm{p}<0.001$, respectively.

HDL2: the concentration of SAA was not related to the degree of CVD-burden or LCAT-activity ( $\mathrm{p}<0.05$ for both correlations). 
HDL3: the concentration of SAA was positively correlated with the degree of CVD-burden $(r=0.252, p<0.001)$ and negatively correlated with the activity of LCAT $(r=-0.182, \mathrm{p}=0.006)$.

\subsection{Multivariate and Receiver operator characteristic curve analyses}

The following covariates were associated with increased significant CVD risk compared to no CVD in a multivariate analysis also adjusted for CRP and serum-SAA (table 4): male gender (odds ratio (OR)=11.9; confidence interval (CI): 4.41-32.2; $\mathrm{p}<1 \times 10^{-5}$ ), age (per year increase; OR=1.16; CI: 1.10-1.21; $\mathrm{p}<1 \times 10^{-5}$ ), and $\mathrm{HDL}_{3}-\mathrm{SAA}$ (per 10-fold increase: $\mathrm{OR}=5.85 ; \mathrm{CI}$ : 1.33-25.7; $\mathrm{p}=0.02$ ). No evidence to support an interaction between any of the covariates within the regression model was found.

Area under the ROC curves (AUC) (CI) illustrated that for model 1-gender, the AUC was 0.680 (0.6080.752, $\mathrm{p}<0.001)$ : For model 2-age, the AUC was $0.724(0.658-0.789, \mathrm{p}<0.001)$ : For model 3-gender+age, the AUC was 0.819 (0.764-0.874, $\mathrm{p}<0.001)$ : For model 4-gender+age+HDL 3 -SAA, the AUC was 0.824 (0.769-0.879, $\mathrm{p}<0.001$ ). These results illustrate that by adding $\mathrm{HDL}_{3}-\mathrm{SAA}$ to the model meant that our predictive power to illustrate the presence of CVD was improved to $82.4 \%$, over that of gender $(68.0 \%)$, age $(72.4 \%)$ and gender+age $(81.9 \%)$. We also reran these models with serum-SAA in the model instead of $\mathrm{SAA}^{-\mathrm{HDL}_{3}}$ and found a reduction in the size of the effect and significance of the association with any CVD.

In addition, when we added HDL-cholesterol to the existing ROC curve, the new estimates were: $0.83(0.776$, 0.884), indicating a slight but non-significant improvement in the AUC ( $\mathrm{p}<0.05)$. Total cholesterol, triglyceride and LDL-cholesterol have no significant effect. Finally, we re-ran the regression models with LCAT activity included as a covariate and identified that LCAT activity did not contribute to the model. 
SAA and its relationship to CVD-burden

\section{Discussion}

To the author's knowledge this is the first cross-sectional study to examine the relationship between CVDburden, inflammation and compositional changes to the main subfractions of $\mathrm{HDL}$, namely $\mathrm{HDL}_{2}$ and $\mathrm{HDL}_{3}$. The main findings were that inflammatory SAA was increased in serum and $\mathrm{HDL}_{3}$ which, in the case of $\mathrm{HDL}_{3}$ was moderately associated with increased risk of significant $\mathrm{CVD}$, proving $\mathrm{HDL}_{3}-\mathrm{SAA}$ to be a sensitive biomarker of CVD-burden and indicating that inflammation was increased in subjects with documented CVD. In addition, the activity of $\mathrm{HDL}_{3}$-LCAT was also weakly influenced by the degree inflammation and CVD severity. We suggest that SAA may be useful prognostic tools in identifying patients with high atherosclerotic burden, and thus increased CVD-risk.

Although the measurement of serum-hsCRP is established as a biomarker of CVD-risk, the current study was unable to identify such an association, although we did identify that hsCRP was significantly higher in the group with significant-CVD, compared to the no-CVD group ( $\mathrm{p}=0.049)$. We, therefore, suggest that although hsCRP is the most extensively studied biomarker linked to the pathophysiology of atherosclerosis[25], it may only be at the advanced stages of CVD that it may be predicative. However, we were able to demonstrate that serumSAA was related to the degree of CVD-burden and that a strength of this study was the fact that none of our subjects were on lipid-lowering medication, especially statins, which are known to lower SAA[41], thus removing any confounding influence that these drugs may have displayed on our findings. Our findings are consistent with previous studies that have proposed serum-SAA as sensitive biomarker to illustrate increased inflammation[3,2728]. In the circulation, SAA rapidly associates with HDL, where it renders this lipoprotein dysfunctional with numerous proinflammatory actions[9-11], which include reduced antioxidant capacity[15] and reduced RCT capabilities[10]. Thus, as the current study was also able to demonstrate that the increase in serum-SAA augmented its association with $\mathrm{HDL}$, particularly $\mathrm{HDL}_{3}$, the $\mathrm{HDL}$ subfraction more closely associated with $\mathrm{SAA}$ [8], this illustrates that $\mathrm{HDL}_{3}$ was potentially proatherogenic in the subjects with significant-CVD burden. This concept is driven by the documented proof that when HDL is associated with SAA it displays diminished antiatherogenic properties[11]. In further support of our findings, a recent publication by Zewinger et al[29] reported that SAA modified the biological effects of HDL-cholesterol in several clinical conditions.

The current study also identified lower $\mathrm{HDL}_{3}$-LCAT activity in the subjects with increased CVD-burden, again indicating $\mathrm{HDL}_{3}$ subfractions with a more proatherogenic phenotype. Furthermore, as the mass of LCAT was not different between the groups, it would suggest that functional changes had occurred within this enzyme. This concept corroborates gene studies, where heterozygous carries of mutations in the LCAT gene display 
reduced LCAT activity, concomitant with a reduction in HDL-cholesterol. Furthermore, reduced LCAT function has been associated with increased atherosclerosis, as measured by intimal media thickness[30]. This latter study also suggested that increasing LCAT activity may not only increase serum HDL-cholesterol, but also decrease inflammation in the form of hsCRP. This concept was supported, in part, by the current findings where inflammation, in the form of $\mathrm{HDL}_{3}$-SAA, was decreased in the subjects with increased $\mathrm{HDL}_{3}$-LCAT activity. This model was strengthened by the negative correlation identified between $\mathrm{HDL}_{3}$-LCAT activity and $\mathrm{HDL}_{3}$-SAA. However, evaluation of this relationship would require further investigation via a longitudinal study to fully explore the influence of CVD-burden and its impact on the activity of HDL-LCAT. This would be particular pertinent, as the protective role of LCAT in the development/progression of CVD is contested, as several studies have indicated that decreased LCAT activity and mass are not associated with cardio-protection[17] and does not predict adverse cardiac events, while others suggest that higher LCAT activity was associated with increased intima thickness and was a risk for CHD and sudden death. Furthermore, in the review by Frohlich's group, who documented that in subjects with complete deficiency of LCAT, their increased atherosclerosis may be related to low LDL levels and not the lack of LCAT[18].

\section{Study Limitations}

There are several limitations to the present study. Firstly, the cholesterol efflux abilities of HDL were not examined, which would definitively confirm if HDL had reduced RCT capabilities. Secondly, it was also interesting to note that addition of $\mathrm{HDL}_{3}$-SAA to our regression model did not significantly improve the area under the ROC curve, with only a moderate increase from 0.819 to 0.824 (a point of note: the P values quoted within the various models relates to the significance of the predictive value of the parameters included in the model and are not a reflection of the comparison between the models). Evaluation of risk prediction models requires the use of model performance measures, such as the popular ROC metric. Its probabilistic interpretation of its value is based upon the ability of the models' predicted probabilities to correctly discriminate between randomly selected diseased and non-diseased participants. However, it is not uncommon for the area under the ROC curve to show only small and non-significant improvements, even for a predictor variable that makes a significant independent contribution in a logistic regression analysis. More recently, alternative methods for evaluating the usefulness of a new marker have been proposed, including event-specific reclassification tables and integrated (average) sensitivity, although these methodologies are more typically used in cohort rather than case-control studies. 
SAA and its relationship to CVD-burden

\section{Conclusion}

This study has provided moderate evidence that SAA differs according to the degree of CVD-burden, which was specifically applicable to $\mathrm{HDL}_{3}$-SAA following regression analysis and adjustment for other covariates. This finding confirms $\mathrm{HDL}_{3}$-SAA as a useful and sensitive biomarker of increased CVD and provides a means of assessing CVD-burden. Additionally, this study illustrated that increased CVD-burden impacted, although less strongly, on functional properties of $\mathrm{HDL}_{3}$, as shown by what could be proatherogenic changes to the activity of LCAT. This study adds to the existing portfolio of the importance of functional HDL to reduce CVD and establishes SAA as a candidate biomarker to aid in the diagnosis of CVD-burden. 
SAA and its relationship to CVD-burden

\section{References}

1. R.W. Alexander. Inflammation and coronary artery disease. N Engl. J. Med. 331 (1994) 468-469 doi:10.1056/NEJM199408183310709.

2. P. Libby, M. Ridker, A. Maseri. Inflammation and atherosclerosis. Circulation. 105 (2002) 1135-1143 doi: $10.1161 / \mathrm{hc} 0902.104353$.

3. I. Ikonomidis, K. Stamatelopoulos, J. Lekakis, G.D. Vamvakou, D.T. Kremastinos. Inflammatory and non-invasive vascular markers: the multimarker approach for risk stratification in coronary artery disease. Atherosclerosis. 199 (2008) :3-11 doi: 10.1016/j.atherosclerosis.2008.02.019.

4. J.C. Betts, J.K. Cheshire, S. Akira, T. Kishimoto, P. Woo P. The role of NF-kappa B and NF-IL6 transactivating factors in the synergistic activation of human serum amyloid A gene expression by interleukin-1 and interleukin-6. J. Biol. Chem. 26 (1993) 25624-25631.

5. T. Gordon, W.P. Castelli, M.C. Hjortland, W.B. Kannel, T.R. Dawber. High density lipoprotein as a protective factor against coronary heart disease: the Framingham Study. Am. J. Med. 62 (1997) 707-714 doi: 10.1016/0002-9343(77)90874-9.

6. V. Manninen, L. Tenkanen, P. Koskinen, J.K. Huttunen, M. Mänttäri, O.P. Heinonen, M.H. Frick. Joint effects of serum triglyceride and LDL cholesterol and HDL cholesterol concentrations on coronary heart disease risk in the Helsinki Heart Study: implications for treatment. Circulation. 85 (1992) 37-45 doi: 10.1161/01.CIR.85.1.37.

7. F.C. McGillicuddy, M. de la Llera, C.C. Hinkle, M.R. Joshi, E.H. Chiquoine, J.T. Billheimer, G.H. Rothbat, M.P. Reilly. Inflammation impairs reverse cholesterol transport in vivo. Circulation. 119 (2009) 1135-1145 doi: 10.1161/CIRCULATIONAHA.108.810721.

8. N. Eriksen, E.P. Benditt. Isolation and characterization of the amyloid-related apoprotein (SAA) from human high density lipoprotein. Proc. Natl. Acad. Sci. USA. 77 (1980) 6860-6864.

9. A. Artl, G. Marsche, S. Lestavel, W. Sattler, E. Malle. Role of serum amyloid A during metabolism of acute-phase HDL by macrophages. Arterioscler. Thromb. Vasc. Biol. 20 (2000) 763-772 doi: 10.1161/01.ATV.20.3.763.

10. J.B. Ancsin, R. Kisilevsky. Serum amyloid A peptide interactions with glycosaminoglycans. Evaluation by affinity chromatography. Methods Mol. Biol. 171 (2001) 449-456 doi:10.1385/1-59259-209-0:449. 
11. T. Vaisar, C. Tang, I. Babenko, P. Hutchins, J. Wimberger, A.F. Suffredini, J.W. Heinecke. Inflammatory remodelling of the HDL proteome impairs cholesterol efflux capacity. J. Lipid Res. (2015) pii: jlr.M059089. (Epub ahead of print).

12. E. Hatanaka, C.J. Furlaneto, F.P. Ribeiro, G.M. Souza, A. Campa. Serum amyloid A induces mRNA expression and release of tumour necrosis factor- $\alpha(\mathrm{TNF}-\alpha)$ in human neutrophils. Immunol. Lett. 91 (2004) 33-37 doi:10.1016/j.imlet.2003.09.011.

13. H. Cai, C. Song, I. Endoh, J. Goyette, W. Jessup, S.B. Freedman, H.P McNeil, C.L. Geczy. Serum amyloid A induces monocyte tissue factor. J. Immunol. 178 (2007) 1852-1860 doi: 10.4049/jimmunol.178.3.1852.

14. C.M. Uhlar, A.S. Whitehead. Serum amyloid A, the major vertebrate acute phase reactant. Eur. J. Biochem. 265 (1999) 501-523 doi: 10.1046/j.1432-1327.1999.00657.x.

15. R.P. Dullaart, J.F. de Boer, W. Annema, U.J. Tietge. The inverse relation of HDL anti-oxidative functionality with serum amyloid a is lost in metabolic syndrome subjects. Obesity. 21 (2013) 361-366. doi: 10.1002/oby.20058.

16. K.H. Cho, S.H. Park, J.E., Park, Y.O., Kim, I. Choi, J.J., Kim, J.R. Kim. The function, composition and particle size of high density lipoprotein were severely impaired in an oliguric phase of hemorrhagic fever with renal syndrome patients. Clin. Biochem. 41 (2008) 56-64 doi:10.1016/j.clinbiochem.2007.10.007.

17. A.G. Holleboom, J.A. Kuivenhoven, M. Vergeer, G.K. Hovingh, J.N. van Miert, N.J. Wareham, J.J. Kastelein, K.T. Khaw, S.M. Boekholdt. Plasma levels of lecithin:cholesterol acyltransferase and risk of future coronary artery disease in apparently healthy men and women: a prospective case-control analysis nested in the EPIC-Norfolk population study. J. Lipid Res. 51 (2010) 416-21. doi: 10.1194/P900038JLR200.

18. R. Saeedi M. Li, J. Frohlich. A review of lecithin:cholesterol acyltransferase deficiency. Clin. Biochem. 48 (2015) 472-475. doi: 10.1016/j.clinbiochem.2014.08.014.

19. U.J. Schoepf, P.L. Zwerner, G. Savino, C. Herzog, J.M. Kerl, P. Costello. Coronary CT angiography. Radiology. 244 (2007) 48-63. doi.org/10.1148/radiol.2441052145.

20. P. McKavanagh, L. Lusk, P.A. Ball, R.M. Verghis, A.M. Agus, T.R. Trinick, E. Duly, G.M. Walls, M. Stevenson, B. James, M.T. Harbinson, P.M. Donnelly. A comparison of cardiac computerized tomography and exercise stress electrocardiogram test for the investigation of stable chest pain: the 
SAA and its relationship to CVD-burden

clinical results of the CAPP randomised prospective trial. Eur. Heart J. Cardiovasc. Imaging. (2014). (Epub ahead of print) doi: jeu284.

21. T.A. Pearson, G.A. Mensah, R.W. Alexander, J.L. Anderson, R.O. Cannon 3rd, M. Criqui. Markers of inflammation and cardiovascular disease: application to clinical and public health practice: a statement for healthcare professionals from the Centres for Disease Control and Prevention and the American Heart Association. Circulation. 107 (2003) 499-511doi: 10.1161/01.CIR.0000052939.59093.45.

22. A.J. Taylor, M. Cerqueira, J.McB. Hodgson, D. Mark, J. Min, P. O'Gara, G.D. Rubin, ACCF/SCCT/ACR/AHA/ASE/ASNC/NASCI/SCAI/SCMR. Appropriate use criteria for cardiac computed tomography. A Report of the American College of Cardiology Foundation Appropriate Use Criteria Task Force, the Society of Cardiovascular Computed Tomography, the American College of Radiology, the American Heart Association, the American Society of Echocardiography, the American Society of Nuclear Cardiology, the North American Society for Cardiovascular Imaging, the Society for Cardiovascular Angiography and Interventions, and the Society for Cardiovascular Magnetic Resonance. J. Am. Coll. Cardiol. 56 (2010) 1864-1894 doi: 10.1016/j.jacc.2010.07.005.

23. P.A. McPherson, I.S. Young, B. McKibben, J McEneny. High density lipoprotein subfractions: isolation, composition, and their duplicitous role in oxidation. J. Lipid Res. 48 (2007) 86-95 doi: 10.1194/jlr.M600094-JLR200.

24. E.R. DeLong, D.M. DeLong, D.L. Clarke-Pearson. Comparing the areas under two or more correlated receiver operating characteristic curves: a nonparametric approach. Biometrics. 44 (1988) 837-845 doi:10.2307/2531595.

25. D.A. Silva, A. Pais de Lacerda. High-sensitivity C-reactive protein as a biomarker of risk in coronary artery disease. Rev. Port. Cardiol. 31 (2012) 733-745 doi: 10.1016/j.repc.2012.02.018.

26. S. Kinlay G.G. Schwartz, A.G. Olsson, N. Rifai, S.J. Leslie, W.J. Sasiela, M. Szarek, P. Libby, P. Ganz, Myocardial Ischemia Reduction with Aggressive Cholesterol Lowering Study Investigators. 2004. Myocardial Ischemia Reduction with Aggressive Cholesterol Lowering Study Investigators. High-dose atorvastatin enhances the decline in inflammatory markers in patients with acute coronary syndromes in the MIRACL study. Circulation. 108 (2004) 1560-1566.

27. S. Bozinovske, A. Hutchinson, M. Thompson M.L. Macgregor, J. Black, E. Giannakis, A.S. Karlsson, R. Silvestrini, D. Smallwood, R. Vlahos, L.B. Irving, G.P. Anderson. Serum amyloid a is a biomarker of 
SAA and its relationship to CVD-burden

acute exacerbations of chronic obstructive pulmonary disease. Am. J. Resp. Crit. Care Med. 177 (2008) 269-278 doi: 10.1164/rccm.200705-678OC.

28. J. McEneny, L. Wade, I.S. Young, L. Masson, G. Duthie, A. McGinty, C. McMaster, F. Thies. Lycopene intervention reduces inflammation and improves HDL functionality in moderately overweight middle-aged individuals. J. Nutr. Biochem. 24 (2013) 163-168 doi: 10.1016/j.jnutbio.2012.03.015.

29. S. Zewinger, C. Drechsler, M.E. Kleber, A. Dressel, J. Riffel, S. Triem, M. Lehmann, C. Kopecky, M.D. Säemann, P.M. Lepper, G. Silbernagel, H. Scharnagl, A. Ritsch, B. Thorand, T. de Las Heras Gala, S. Wagenpfeil, W. Koenig, A. Peters, U. Laufs, C. Wanner, D. Fliser, T. Speer, W. März. Serum amyloid A: high-density lipoproteins interaction and cardiovascular risk. Eur. Heart J. Epub ahead of print (2015) pii: ehv352.

30. G.K. Hovingh, B.A. Hutten, A.G. Holleboom, W. Petersen, P. Rol, A. Stalenhoef, A. H. Zwinderman, E. de Groot, J.J. Kastelein, J.A. Kuivenhoven. Compromised LCAT function is associated with increased atherosclerosis. Circulation. 112 (2005) 879-884 doi: 10.1161/CIRCULATIONAHA.105.540427. 
SAA and its relationship to CVD-burden

Table 1. Subject Characteristics according to CVD-burden

\begin{tabular}{|c|c|c|c|c|}
\hline & $\begin{array}{l}\text { No-CVD } \\
(\mathrm{n}=102)\end{array}$ & $\begin{array}{c}\text { Non-Obstructive-CVD } \\
(\mathrm{n}=58)\end{array}$ & $\begin{array}{c}\text { Moderate/Significant- } \\
\qquad \text { CVD (n=74) } \\
\end{array}$ & $\begin{array}{l}\text { Oneway } \\
\text { ANOVA }\end{array}$ \\
\hline Age (years) & $53.8(8.8)^{\mathrm{a}}$ & $56.8(8.6)^{\mathrm{b}}$ & $64.6(9.5)^{\mathrm{c}}$ & $<0.001$ \\
\hline Gender (\% Male) & $40^{\mathrm{a}}$ & $74^{\mathrm{b}}$ & $72^{\mathrm{b}}$ & $<0.001$ \\
\hline BMI $\left(\mathbf{k g} / \mathbf{m}^{2}\right)$ & $27.5(3.5)$ & 27.6(3.9) & $28.0(3.5)$ & 0.576 \\
\hline Total Chol (mmol/L) & $5.54(1.09)^{\mathrm{a}}$ & $5.30(1.16)^{\mathrm{ab}}$ & $5.03(1.09)^{\mathrm{b}}$ & 0.011 \\
\hline Trigs (mmol/L) & $1.33(0.76)$ & $1.44(0.77)$ & $1.48(0.86)$ & 0.424 \\
\hline LDL Chol (mmol/L) & $3.32(0.96)$ & $3.23(1.00)$ & $3.00(0.95)$ & 0.076 \\
\hline HDL Chol (mmol/L) & $1.64(0.50)^{\mathrm{a}}$ & $1.42(0.42)^{\mathrm{b}}$ & $1.39(0.45)^{\mathrm{b}}$ & 0.001 \\
\hline Area of Stenosis (AU) & $0.00(0.00)^{\mathrm{a}}$ & $2.79(1.95)^{\mathrm{b}}$ & $12.28(7.82)^{\mathrm{c}}$ & $<0.001$ \\
\hline Calcium Scores (\%) & $0.00(0.00)^{\mathrm{a}}$ & $45.91(34.58)^{\mathrm{b}}$ & $70.18(24.51)^{\mathrm{c}}$ & $<0.001$ \\
\hline Lipid Lowering Therapy (n) & $14^{\mathrm{a}}$ & $18^{\mathrm{bc}}$ & $30^{\mathrm{c}}$ & $<0.001$ \\
\hline ACE Inhibitor Therapy (n) & 9 & 7 & 11 & 0.133 \\
\hline T2DM (n) & 3 & 3 & 7 & 0.203 \\
\hline Smokers (n) & 18 & 12 & 13 & 0.571 \\
\hline
\end{tabular}

Results expressed as mean(SD) or as geometric mean(interquartile range) if not normally distributed. Similar superscript letters indicate no differences between groups, and different superscript letters indicate differences between groups (significance set at $\mathrm{p} \leq 0.05$ ).

CVD; cardiovascular disease: BMI; body mass index: Chol; cholesterol: Trigs; triglycerides: LDL; low density lipoproteins: HDL; high density lipoprotein: Area of stenosis is expressed as arbitrary units (AU) and is evaluated by The American Heart Association's 15-point scale[22], which is a division of the coronary tree divided in to 15 parts, multiplied by the severity of stenosis in each part. 
Table 2. hsCRP and SAA according to CVD-burden

\begin{tabular}{|c|c|c|c|c|}
\hline & $\begin{array}{l}\text { No-CVD } \\
(n=102)\end{array}$ & $\begin{array}{l}\text { Non-Obstructive-CVD } \\
\qquad(\mathrm{n}=58)\end{array}$ & Moderate/Significant-CVD $(n=74)$ & $\begin{array}{l}\text { Oneway } \\
\text { ANOVA }\end{array}$ \\
\hline Serum-hsCRP ( $\mu$ g hsCRP/L) & $1900(630,2732)$ & $2100(690,2884)$ & $2380(961,3003)$ & 0.270 \\
\hline Serum-SAA $(\mu \mathrm{g} \mathrm{SAA} / L)$ & $16216(7452,23186)^{\mathrm{a}}$ & $16675(7240,21146)^{\mathrm{a}}$ & $21605(9468,25651)^{\mathrm{b}}$ & 0.046 \\
\hline HDL $_{2}-\mathbf{S A A}(\boldsymbol{\mu g} \mathrm{SAA} / \mathrm{L})$ & $1278(445,1826)$ & $1208(408,1789)$ & $1632(465,2204)$ & 0.121 \\
\hline HDL $_{2}-\mathrm{SAA}(\mu \mathrm{g} \mathrm{SAA} / \mathrm{mg}$ protein) & $3.59(1.61,5.56)^{\mathrm{a}}$ & $5.03(2.83,6.24)^{\mathrm{a}, \mathrm{b}}$ & $5.67(2.58,6.96)^{\mathrm{b}, \mathrm{c}}$ & 0.012 \\
\hline HDL $_{3}-\mathrm{SAA}(\boldsymbol{\mu g} \mathrm{SAA} / \mathrm{L})$ & $11748(5054,17237)^{\mathrm{a}}$ & $11648(4407,16314)^{\mathrm{a}}$ & $16614(7193,17640)^{\mathrm{b}}$ & 0.016 \\
\hline HDL3-SAA ( $\mu$ g SAA/mg protein) & $2.69(1.37,3.73)^{\mathrm{a}}$ & $3.19(1.31,4.60)^{\mathrm{a}, \mathrm{b}}$ & $4.44(1.88,5.38)^{\mathrm{c}}$ & $<0.001$ \\
\hline
\end{tabular}

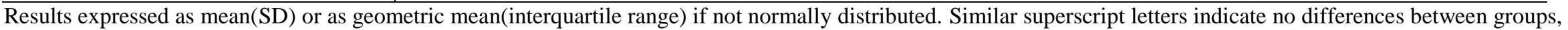
different superscript letters indicate differences between groups (significance set at $\mathrm{p} \leq 0.05$ ).

CVD; cardiovascular disease: hsCRP; high sensitive C-reactive protein: SAA; serum amyloid A: HDL; high density lipoprotein. 
SAA and its relationship to CVD-burden

Table 3. HDL2 and HDL3-LCAT activity and mass according to CVD-burden

\begin{tabular}{|c|c|c|c|c|}
\hline & $\begin{array}{l}\text { No-CVD } \\
(n=102)\end{array}$ & $\begin{array}{c}\text { Non-Obstructive- } \\
\text { CVD (n=58) }\end{array}$ & $\begin{array}{c}\text { Moderate/Significant- } \\
\text { CVD }(n=74)\end{array}$ & $\begin{array}{l}\text { Oneway } \\
\text { ANOVA }\end{array}$ \\
\hline \multicolumn{5}{|c|}{ LCAT Activity } \\
\hline HDL $_{2}$ (ratio) & $0.15(0.02)$ & $0.15(0.02)$ & $0.15(0.02)$ & 0.473 \\
\hline $\mathrm{HDL}_{3}$ (ratio) & $1.32(0.19)^{\mathrm{a}}$ & $1.28(0.20)^{\mathrm{a}}$ & $1.24(0.21)^{\mathrm{b}}$ & 0.022 \\
\hline \multicolumn{5}{|l|}{ LCAT Mass } \\
\hline $\mathrm{HDL}_{2}(\mu \mathrm{g} / \mathrm{L})$ & $1220(658)$ & 1021(689) & $1139(686)$ & 0.202 \\
\hline $\mathrm{HDL}_{3}(\mu \mathrm{g} / \mathrm{L})$ & 4941(1705) & $4493(1290)$ & $4840(1668)$ & 0.229 \\
\hline
\end{tabular}

Results expressed as mean(SD) or as geometric mean(interquartile range) if not normally distributed. Similar superscript letters indicate no differences between groups, different superscript letters indicate differences between groups (significance set at $\mathrm{p} \leq 0.05$ ).

CVD; cardiovascular disease: LCAT; lecithin cholesteryl acyl transferase: HDL; high density lipoprotein. 
Table 4. Multivariate analysis of CVD risk factors with change in risk reflected by odds ratios, confidence intervals and $P$ values

\begin{tabular}{|c|c|c|c|}
\hline Covariate & $\begin{array}{l}\text { Odds ratio(CI); P value } \\
\text { Any CVD vs No CVD }\end{array}$ & $\begin{array}{c}\text { Odds ratio(CI); P value } \\
\text { Significant CVD vs No CVD }\end{array}$ & $\begin{array}{c}\text { Odds ratio(CI); P value } \\
\text { Significant CVD vs No or mild CVD }\end{array}$ \\
\hline $\begin{array}{l}\text { Gender } \\
\text { (male compared to female) }\end{array}$ & $9.06(4.22-19.5) ;<1 \times 10^{-5}$ & $11.9(4.41-32.2) ;<1 \times 10^{-5}$ & $5.89(2.60-13.4) ;<1 \times 10^{-5}$ \\
\hline $\begin{array}{l}\text { Age } \\
\text { (per year increase) }\end{array}$ & $1.12(1.07-1.16) ;<1 \times 10^{-5}$ & $1.16(1.10-1.21) ;<1 \times 10^{-5}$ & $1.14(1.09-1.19) ;<1 \times 10^{-5}$ \\
\hline $\begin{array}{l}\mathrm{SAA} \mathrm{HDL}_{3} \\
\text { (per } 10 \text { fold increase) }\end{array}$ & $1.71(0.47-6.22) ; 0.41$ & $5.85(1.33-25.7) ; 0.02$ & $5.91(1.54-22.7) ; 0.01$ \\
\hline $\begin{array}{l}\text { Serum-SAA } \\
\text { (per } 10 \text { fold increase) }\end{array}$ & $1.70(0.44-6.54) ; 0.44$ & $1.44(0.30-6.95) ; 0.65$ & $0.86(0.21-3.52) ; 0.84$ \\
\hline CRP & $1.00(0.83-1.21) ; 0.99$ & 1.04 (0.84-1.29); 0.74 & $1.08(0.89-1.31) ; 0.43$ \\
\hline
\end{tabular}

Change in risk is when we compared any CVD and significant CVD with no CVD or no or mild CVD 